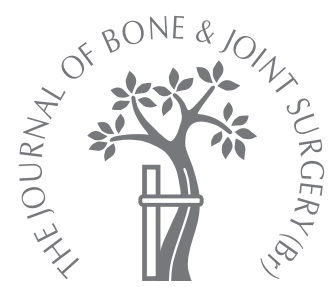

\title{
Uncemented custom computer-assisted design and manufacture of hydroxyapatite- coated femoral components
}

\author{
SURVIVAL AT 10 TO 17 YEARS
}

S. K. Muirhead-

Allwood,

N. Sandiford,

J. A. Skinner,

J. Hua,

C. Kabir,

P. S. Walker

From The London

Hip Unit, London,

United Kingdom
=S. Muirhead-Allwood, FRCS, Consultant Orthopaedic Surgeon

N. Sandiford, MRCS MFSEM, Specialist Registrar - C. Kabir, MRCS, Clinical Research Fellow

The London Hip Unit, 4th Floor, 30 Devonshire Street, London W1G 6PU, UK.

I. J. Skinner, FRCS(Orth), Consultant Orthopaedic Surgeon

J. Hua, PhD, Director of Biomedical Engineering The Royal National Orthopaedic Hospital,

Stanmore, Middlesex HA7 4LP UK.

E. S. Walker, PhD, Professor, Director

MIS Laboratory, Department of Orthopaedic Surgery NYU Medical Center - Hospital for Joint Diseases, 301 East 17th Street, Manhattan, New York 10003, USA.

Correspondence should be sent to $\mathrm{Mr}$ N. Sandiford; e-mail: nemsandiford@hotmail.com

(c)2010 British Editorial Society of Bone and Joint Surgery doi:10.1302/0301-620X.92B8. $23123 \$ 2.00$

$J$ Bone Joint Surg [Br] 2010;92-B:1079-84. Received 21 July 2009; Accepted after revision 14 April 2010

We present the 10- to 17-year results of 112 computer-assisted design computer-assisted manufacture femoral components. The total hip replacements were performed between 1992 and 1998 in 111 patients, comprising 53 men and 58 women. Their mean age was 46.2 years (24.6 to 62.2) with a mean follow-up of 13 years (10 to 17). The mean Harris Hip Score improved from 42.4 (7 to 99 ) to 90.3 (38 to 100), the mean Oxford Hip Score from 43.1 (12 to 59 ) to 18.2 (12 to 51) and the mean Western Ontario MacMasters University Osteoarthritis Index score from $\mathbf{5 7 . 0}$ (7 to 96 ) to 11.9 ( 0 to 85 ). There was one revision due to failure of the acetabular component but no failures of the femoral component. There were no revisions for aseptic loosening. The worst-case survival in this cohort of custom femoral components at $\mathbf{1 3 . 2}$ years follow-up was $\mathbf{9 8 . 2} \%$ (95\% confidence interval 95 to 99 ). Overall survival of this series of total hip replacements was $97.3 \%$ (95\% confidence interval 95 to 99 ).

These results are comparable with the best medium- to long-term results for femoral components used in primary total hip replacement with any means of fixation.

Uncemented total hip replacement (THR) is now a standard surgical option in the treatment of end-stage arthritis of the hip. It provides excellent relief of pain with low rates of complications in appropriately selected patients. ${ }^{1}$ Good long-term results have been reported using uncemented implants in other patient populations. ${ }^{2,3}$

With some designs of component there is a risk of stress shielding of the proximal femur causing resorption of proximal femoral bone and bone loss. ${ }^{4}$ Optimal results rely on obtaining initial stability, contact over the entire ingrowth surface and uniform stress transfer to the proximal femur. ${ }^{5}$ Secondary bone ingrowth and stable long-term fixation also depend on achieving primary stability. The high degree of anatomical variation among patients ${ }^{6}$ can make this a challenge with off the shelf prostheses. Achieving ideal fit and stability requires reshaping of the medullary canal to conform to the chosen implant. This requires excision of bone and creates areas of stress concentration and subsequent stress shielding. ${ }^{5}$ Anatomical variation includes the endosteal shape of the metaphysis of the proximal femur as well as the extramedullary characteristics such as the anteversion and offset of the femoral neck and the neck-shaft angle. ${ }^{7}$

In attempting to recreate a hip joint which is biomechanically and physiologically as close as possible to the patient's normal hip, these factors must all be considered. An alternative is, therefore, to conform the shape and design of the prosthesis to the existing proximal femur.

Custom computer assisted design-computer assisted manufactured (CAD-CAM) femoral components are tailored to fit the metaphysis of the proximal femur, optimising both fit and fill, and to recreate the extramedullary anatomy. The bone therefore requires much less reshaping.

Good clinical and radiological results using custom femoral components have been reported in younger patients with deformity and osteoarthritis secondary to hip dysplasia ${ }^{8,9}$ and congenital dislocation. ${ }^{10}$ Improved longterm functional outcomes have also been described. ${ }^{11}$ Likewise encouraging results have been observed in young patients without anatomical abnormalities. ${ }^{7}$

This prospective study presents the results of a single surgeon series of 112 primary THRs in 111 patients using uncemented CAD-CAM prostheses at a minimum follow-up of ten years.

\section{Patients and Methods}

A total of 113 patients (114 hips) underwent primary THR using CAD-CAM femoral components between 1991 and 1997. Two patients (two hips) did not wish to attend regular follow-up for this study and were excluded, 
Table I. Patient characteristics

\begin{tabular}{ll}
\hline & Number of patients \\
\hline Total & 111 (112 hips) \\
$\quad$ Male & 53 \\
$\quad$ Female & 58 \\
& \\
Mean age in years (range) & $46.3 \quad(24.6$ to 62.2$)$ \\
$\quad$ Male & $47.2 \quad(27.4$ to 51.6$)$ \\
$\quad$ Female & 45.2 (24.6 to 62.2$)$ \\
& \\
Number & \\
$\quad<55$ years & 99 \\
$\quad>55$ years & 14 \\
&
\end{tabular}

Table II. Diagnosis of patient series

\begin{tabular}{lccc}
\hline Diagnosis $^{*}$ & $\begin{array}{l}\text { Number of } \\
\text { patients }\end{array}$ & Male & Female \\
\hline AVN & 8 & 5 & 3 \\
CDH $^{\dagger}$ & 41 & 5 & 36 \\
Osteoarthritis & 45 & 30 & 15 \\
Perthes disease & 5 & 4 & 1 \\
SUFE & 6 & 5 & 1 \\
Septic arthritis & 4 & 4 & 0 \\
RA & 1 & 0 & 1 \\
Morquio's disease & 1 & 0 & 1
\end{tabular}

* AVN, avascular necrosis; $\mathrm{CDH}$, congenital dysplasia of the hip; SUFE, slipped upper femoral epiphysis; RA, rheumatoid arthritis

$+\mathrm{CDH}$ was diagnosed in the bilateral case

leaving 111 patients (112 hips) for evaluation. One patient underwent bilateral procedures at an interval of three months. The mean age of our cohort was 46.2 years $(24.6$ to 62.2$)$ with 99 patients $(89.2 \%)<55$ years of age. There were 53 men $(48 \%)$ and 58 women $(52 \%)$ (Table I). The pre-operative diagnoses are shown in Table II. All patients presented with disabling pain.

\section{Planning and design}

All components were designed and manufactured at the Biomechanical Engineering unit at the Royal National Orthopaedic Hospital, Stanmore, United Kingdom.

The femoral components used in this study were developed using data derived from true anteroposterior radiographs of the pelvis and lateral views of the affected hip. In order to standardise for magnification, a radiopaque ruler was placed adjacent to the pelvis when the measurement films were obtained. The images were then digitised and edge detection software was used to generate a surface model of the endosteal and periosteal surfaces using proprietary software (Stanmore Implants Worldwide, Stanmore, United Kingdom). Digitisation of the radiographs was achieved with a CAMCOMP 9100 surface-lit digitiser (GTCO CAMCOMP Inc, Columbia, Ohio) using software developed at the Centre for Biomedical Engineering, Uni-

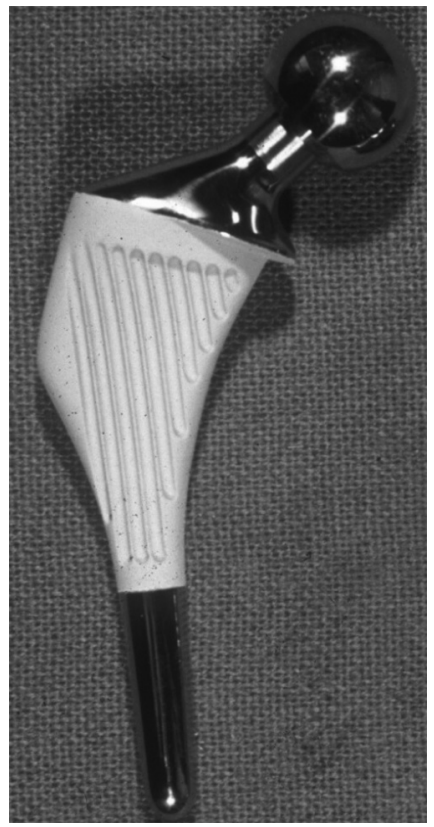

Fig. 1

Photograph showing custom CADCAM femoral component.

versity College London. Based on this information the software was used to construct a three-dimensional model of the femoral canal to facilitate the design of the implant.

These measurements were used by the design engineer to create a CAD template which was returned to the surgeon for analysis and validation. During this process emphasis was placed on establishing the level of the neck osteotomy, restoring the offset and anteversion and the final position of the component relative to the greater and lesser trochanters. Once the final design was approved, the prosthesis was manufactured and sent to the operating theatre along with a custom T-handle straight tapered reamer and broach. The time from final design approval to delivery of the finished product was two weeks.

All implants were manufactured from titanium alloy $\left(\mathrm{Ti}_{6} \mathrm{~A} 1_{4} \mathrm{~V}\right)$. They consisted of a proximal segment which produced a line-to-line fit with the endosteal border of the proximal femur as well as anterior, medial and lateral flares to optimally fit and fill the metaphyseal region. The trunnions were manufactured with a 12/14 Morse taper (Eurotaper) (Fig. 1). The proximal segment was grit-blasted and coated with an $80 \mu \mathrm{m}$ thick layer of high crystallinity hydroxyapatite (HA). The distal third of the stem was polished and tapered to enable accurate orientation within the femoral canal. The mean stem length was $110 \mathrm{~mm}$ $(100 \mathrm{~mm}$ to $120 \mathrm{~mm}$ ) measured from the shoulder of the implant to the tip.

Before the CAD-CAM implants were used in patients, they were mechanically tested for stress distribution, stability and fatigue tolerance in the laboratory. Subsequently a finite- 


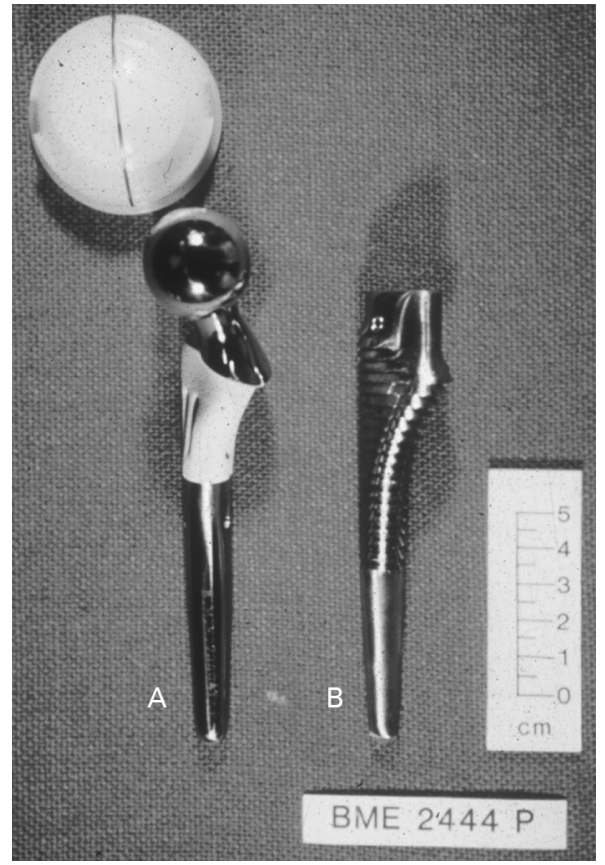

Fig. 2

Photograph showing custom component designed to correct femoral anteversion (A) and with its custom femoral rasp (B).

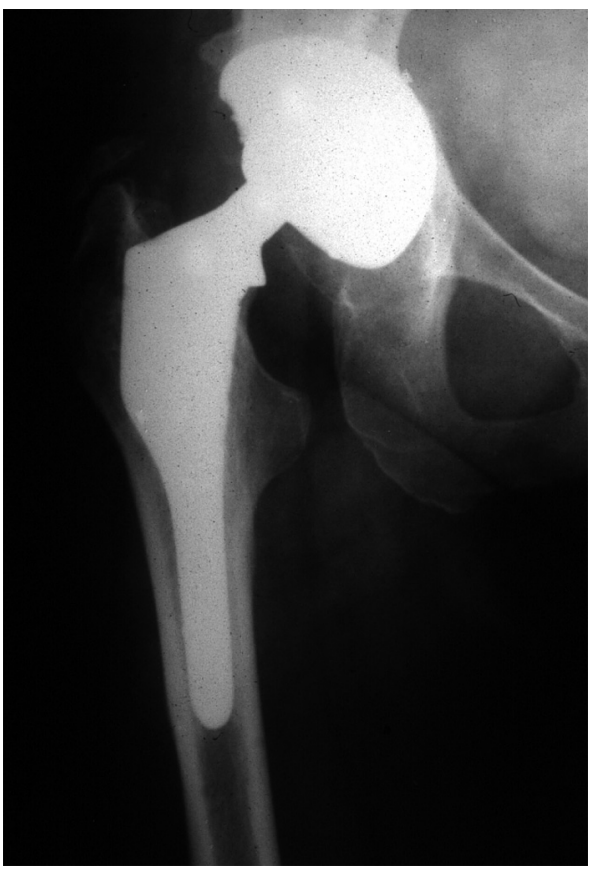

Fig. 3

Radiograph of a custom femoral component at ten year follow-up. element analysis was performed and software for analysing implant strength was developed which allowed the designers to analyse individual patients and implants. The software took into account the body-weight of the patient, the offset and length of the implant, its geometry and material properties, and the location of its fixation.

Surgical technique. All procedures were performed via a standard posterior approach. The femoral cavity was prepared by compaction of the metaphyseal cancellous bone using the custom broach supplied (Fig. 2). This was done in a two-stage process. The canal was identified using a hand held straight tapered reamer and then the broach was used to contour the metaphyseal canal. In some cases where excess cancellous bone remained, this was removed with a curette. Conventional multiple-stage rasping was not performed.

Trilogy uncemented acetabular components (mean diameter: $55 \mathrm{~mm}$ (42 $\mathrm{mm}$ to $62 \mathrm{~mm}$ ), articular material; HMP in 55 cases, ceramic in 57) (Zimmer, Warsaw, Indiana) were used in all cases. All patients mobilised partial weight bearing $(30 \mathrm{~kg}$ ) on the first post-operative day and this continued for four weeks before progressively relinquishing the crutches. The median length of stay in hospital was five days (four to ten).

Clinical review. All patients were reviewed after six weeks, three months, one year and then annually. They were interviewed and examined, the wound was assessed and all surgical and medical complications documented. The Oxford Hip Score $(\mathrm{OHS})^{12}$, the Western Ontario McMaster
Osteoarthritis Index (WOMAC) ${ }^{13}$ and the Harris Hip score $(\mathrm{HHS})^{14}$ were recorded for each patient. A visual analogue scale (VAS) was also performed $(0=$ poor, $10=$ high satisfaction).

Radiological review. Anteroposterior (AP) radiographs of the pelvis and lateral views of the operated hip (Fig. 3) were taken at each visit and reviewed by two independent observers (NS, CK). These were assessed for signs of change of position and orientation of the components along with radiological evidence of loosening or integration. These included lytic lesions, migration (measured as the difference between the shoulder of the implant and the greater trochanter) and radiolucent lines, spot welding at the bone implant interface, trabeculae extending to the uncemented stem as described by Engh, Sychterz and Engh, ${ }^{15}$ as well as the presence of heterotopic bone. ${ }^{16}$ Lytic lesions were defined as balloon-shaped lucencies around the prosthesis. Radiolucent lines were defined as linear lucencies at the bone-prosthesis interface $>2 \mathrm{~mm}$ wide $^{17}$ and occupying $>30 \%$ of any Gruen zone. ${ }^{18}$ Significant stress shielding was considered to be present if there was selective resorption of bone from the calcar region of the femoral neck. ${ }^{19}$

Statistical analysis. The results were analysed using unpaired Student's $t$-tests. Survival analysis was performed with Kaplan-Meier method and calculating 95\% confidence intervals (CI). All analyses were performed using Medcalc Software (MEDALC, Mariakerke, Belgium). Statistical significance was set at a p-value $<0.05$. 


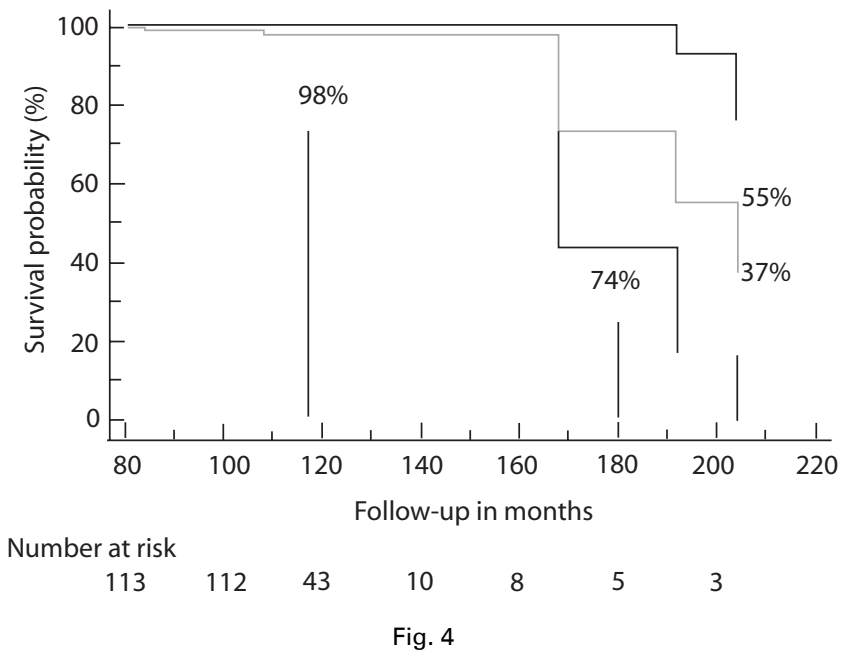

Kaplan-Meier plot (worst-case scenario) with 95\% confidence interval.

\section{Results}

The mean follow-up was 13 years (10 to 17$)$. The mean preoperative OHS, HHS and WOMAC hip scores were 43.1 (12 to 59), 42.4 (7 to 99) and 57.0 (7 to 96) respectively, which improved to a mean at final evaluation of 18.2 (12 to 51), 90.3 (38 to 100 ) and 11.9 (0 to 85), respectively (all analyses $\mathrm{p}<0.001)$. All patients reported excellent pain relief as well as VAS satisfaction. Clinical and functional improvement was achieved rapidly and maintained at the time of the final follow-up. There were no deaths. There were no revisions or impending revisions of the femoral component up to the last review. One patient underwent revision of the acetabular component and femoral head due to failure of the ceramic liner nine years post-operatively. At the final followup 108 hips (96.4\%) had movement up to $120^{\circ}$ measured by a goniometer. Of the four patients who had restricted movement, two were stiff following previous operations since childhood, one was obese and the other patient had pathology of the lumbar spine which restricted hip movement. No patient was restricted in their daily activities and all returned to leisure pursuits including tennis, golf and swimming.

Kaplan-Meier survival analysis was performed with failure defined as revision of the femoral component for any reason. While there were no revisions of the femoral components, two patients were lost to follow-up before ten years, having emigrated at seven and nine years respectively and could not be contacted. These two patients had no pain or other adverse symptoms at their last follow-up. If these are considered as failures then survival of the remaining nine at-risk patients at a mean of 13.2 years is $98.2 \%(95 \% \mathrm{CI}$ 95 to 99) for the femoral components and $97.3 \%$ (95\% CI 95 to 99 ) including the single revision of an acetabular component. If the two lost patients are considered as successes then survival of the femoral component at ten years is $100 \%$. The worst case survival plot is illustrated in Figure 4.
Table III. Distal migration at a mean of 13 years of 103 hips

\begin{tabular}{lll}
\hline & \multicolumn{2}{l}{ Mean distal migration $(\mathbf{m m})$} \\
\cline { 2 - 3 } Mean follow-up (yrs) & All hips $(\mathbf{n}=\mathbf{1 0 1})$ & Hips with RLLs $\left.{ }^{*} \mathbf{n}=\mathbf{2}\right)$ \\
\hline 1 & 0 & 0 \\
5 & 0.4 & 1 \\
13 & 0.2 & 1 \\
\hline * RLLs, radiolucent lines & &
\end{tabular}

\begin{tabular}{ll}
$\begin{array}{l}\text { Table IV. Distribution of radiolu- } \\
\text { cent lines according to the zones } \\
\text { of Gruen et } \text { Il }^{18} \text { at final follow-up }\end{array}$ \\
\hline Zone & Number of hips \\
\hline I & 0 \\
II & 2 \\
III & 0 \\
IV & 0 \\
V & 0 \\
VI & 0 \\
VII & 2 \\
\hline
\end{tabular}

In addition to the two patients lost to follow-up prior to ten years, a further four patients were lost to follow-up between 12 and 16 years but had no complaints when last seen and had returned to their normal activities.

Migration data are presented in Table III. One femoral component had subsided by $2 \mathrm{~mm}$ at the time of the last follow-up. This measurement was made on the AP pelvic radiograph taken four years after operation. It had not progressed over two consecutive radiographs performed one year apart. Radiolucent lines were observed in two radiographs. In both cases these occurred in zones 2 and 7 (Table IV). Of the 112 AP pelvic radiographs there was evidence of Brooker grade $1^{20}$ heterotopic ossification in five hips $(4.5 \%)$ and signs of stress shielding were noted at twoyear follow-up in one hip. For patients lost to follow-up their last available radiographs were included in the analysis. The overall radiological appearances were satisfactory (Fig. 3).

There were two cases of deep-vein thrombosis confirmed by Doppler ultrasound imaging which occurred in one man and one woman aged 37.4 and 29.7 years respectively. In one case this progressed to a pulmonary embolism. Both cases occurred within 30 days post-operatively and were treated successfully with full recovery. One patient had an anaphylactic reaction to an anaesthetic agent which was successfully managed. Intra-operative fracture of the calcar occurred in one case. This was treated using stainless steel cerclage wires. There were no cases of sciatic nerve injury, dislocation or symptomatic leg-length discrepancy.

There were no reports of thigh pain despite specific questioning, which might be attributable to the effect of the low modulus of elasticity of titanium from which the components are manufactured, the fact that they are proximally fixed and polished distally and that they have short stems. 
Table V. Medium to long-term results of hydroxyapatite (HA)-coated femoral components and custom prostheses

\begin{tabular}{|c|c|c|c|c|c|c|}
\hline Authors & $\begin{array}{l}\text { Number of } \\
\text { hips }\end{array}$ & Mean age (range) & $\begin{array}{l}\text { Follow-up years } \\
\text { (range) }\end{array}$ & $\begin{array}{l}\text { Mean post-operative } \\
\text { HHS }^{*}\end{array}$ & $\begin{array}{l}\text { Survival of femoral } \\
\text { component }(\%)\end{array}$ & $\begin{array}{l}\text { Aseptic } \\
\text { loosening (\%) }\end{array}$ \\
\hline \multicolumn{7}{|l|}{ HA coated } \\
\hline Rajaratnam et $\mathrm{al}^{2}$ & 331 & $71.2(31.1$ to 89.8$)$ & 17.5 (15 to 21$)$ & - & 97.4 & 0 \\
\hline Bidar et $\mathrm{al}^{27}$ & 111 & 63.1 (33 to 83$)$ & 13 & 87.3 & 94.3 & 1.3 \\
\hline Blakey et $\mathrm{al}^{39}$ & 352 & 64.4 (28 to 97$)$ & $7.2(5$ to 10$)$ & - & 99 & 1 \\
\hline Skinner et $\mathrm{al}^{25}$ & 100 & 56.8 & 10 & & 100 & 0 \\
\hline Mannan et $\mathrm{al}^{29}$ & 100 & 58.9 & 17 & 89.6 & 98.6 & 1 \\
\hline \multicolumn{7}{|l|}{ Custom } \\
\hline Wettstein et $\mathrm{al}^{7}$ & 62 & 57 (35 to 64$)$ & 7.5 (5.5 to 10.9 ) & 98.8 & 100 & 0 \\
\hline Akbar et $\mathrm{al}^{8}$ & 70 & $35 \quad(22$ to 40$)$ & $14(10$ to 16$)$ & 87 & 100 & 0 \\
\hline Flecher et $a^{10}$ & 97 & $48 \quad(17$ to 72$)$ & 13 (7 to 15$)$ & 93 & 97.4 & 1 \\
\hline Current study & 112 & 46.2 (24.6 to 62.2 ) & $13.2(10$ to 17$)$ & 90.3 & 100 & 0 \\
\hline
\end{tabular}

* HHS, Harris hip score

\section{Discussion}

The ideal prosthesis should re-create a biomechanically normal hip joint by restoring both intra- and extramedullary anatomy, allowing full pain-free activity and last the patient's life span without requiring revision. For an uncemented prosthesIs to achieve this several criteria must be met including attainment of initial stability, uniformity of stress distribution to the proximal femur and restoration of femoral offset and abductor tension. ${ }^{5}$ Cemented prostheses have previously been associated with higher rates of failure in younger patients, ${ }^{21}$ particularly on the acetabular side, which led to increased popularity of hybrid and uncemented prosthesis. Data from the Swedish Hip Registry have reported $4 \%$ to $11 \%$ aseptic loosening rates for hybrid THR. ${ }^{22}$ Contemporary hip resurfacing prostheses have mixed results and are associated with concerns relating to the tissue response to elevated levels of metal ions. ${ }^{23}$ Several designs of uncemented THR have also shown promising results at ten to 17.5 year follow-up with reported survival rates of $94.3 \%$ to $100 \%{ }^{24-30}$ (Table V).

While some authors have questioned the necessity for custom implants, ${ }^{31}$ the results of uncemented custom femoral components with greater than ten-year follow-up have been encouraging although there are relatively few. Flecher et $\mathrm{al}^{11}$ described improved function with these components at up to 15 years, but survival of the femoral component was only $87 \%$. Akbar et $\mathrm{al}^{8}$ reported no femoral failures at a mean of 14 years post-operatively in a population of patients $<40$ years old. Encouraging ten-year survival has also been described in patients with osteoarthritis secondary to congenital dislocation of the hip,,${ }^{9,10}$ and high levels of patient satisfaction, functional improvement and absence of revision up to ten years has been noted in patients without femoral deformity using custom components. $^{7}$ In our series we commenced the use of these components in patients with anatomical abnormalities. This proved so effective that their use was extended to all patients. We report $100 \%$ survival of the femoral component in the best case scenario at 13.2 years of follow-up.
These results match the best results published for HAcoated 'off the shelf' components as well as custom components (Table V). They also meet the targets set by the National Institute for Health and Clinical Excellence ${ }^{32}$ as well as the Orthopaedic Data evaluation Panel ${ }^{33}$ even if only the worst scenario is considered.

While endosteal bone can be reamed to obtain a good fit, for the femoral component this involves excision of some bone which weakens the supporting cortex of the proximal femur, creates stress concentrations, non-uniform stress transfer to the proximal femur and undesirable long-term remodelling. ${ }^{5}$ Preparation of the proximal femur for these custom-made components was a two-stage process which predominantly resulted in compaction and minimal removal of metaphyseal cancellous bone. Compaction is associated with a spring back effect which results in intimate contact between the bone and prosthesis, ${ }^{34}$ which improves primary stability and might contribute to these components reproducing relatively anatomical strain patterns along the proximal femur thereby minimising the risk of stress shielding. ${ }^{35}$

Though each femoral component is unique, they are based on exactly the same design principles. ${ }^{36,37}$ Of the 111 patients (112 hips) reviewed, the mean age was 43.6 (24.6 to 62.2 ) years with $93.4 \%<55$ years of age. All were back to their normal work, leisure and sporting activities at six months post-operatively.

In order to meet the requirements of all patients a large inventory of off the shelf components is often necessary. Each custom component used in this study, along with the broach provided, cost approximately $£ 1200$, to which the cost of the AP and lateral radiographs should be added. This is only slightly more expensive than some implants available commercially in the United Kingdom and is less expensive than other custom implants which often require costly threedimensional reconstruction CT scans for design purposes. ${ }^{7}$

Our uncemented prostheses have been based on design features popularised by other uncemented femoral components. ${ }^{2,5}$ By applying philosophies of proximal fit and fill with proximal loading of bone and a distally polished stem 
we were able to demonstrate excellent results, low complications, no thigh pain and only one case of early subsidence. Similar outcomes have been reported in young patients with chronic inflammatory polyarthropathy and abnormal proximal femoral anatomy although the failure rates were higher at ten years, particularly in patients $<16$ years of age. ${ }^{19}$

With the intimate bone contact provided by this design it might be considered that the HA is unnecessary. We recognised that excellent long-term results have been obtained with porous-coated implants although in an older population. ${ }^{38}$ However our philosophy remains that HA is a helpful adjunct in establishing primary fixation especially where there is suboptimal anatomy as in many of our patients. This component was originally intended for implantation in the presence of unusual anatomy but seemed so successful that its use was extended as a primary implant.

Nevertheless, given their cost and the modular options commercially available it would be difficult to recommend custom femoral components as the primary option in the management of patients without morphological abnormalities. Our results suggest that custom HA-coated CADCAM femoral components provide excellent pain relief, satisfaction scores and return to function in the medium to long-term and provide a reasonable option which can be considered where the technology is available, particularly in patients with unusual anatomy.

No benefits in any form have been received or will be received from a commercial party related directly or indirectly to the subject of this article.

\section{References}

1. Stulberg SD, Stulberg BN, Wixson RL. The rationale, design characteristics, and preliminary results of a primary custom total hip prosthesis. Clin Orthop 1989;249:79-96.

2. Rajaratnam SS, Jack C, Tavakkolizadeh A, et al. Long-term results of a hydroxyapatite-coated femoral component in total hip replacement: a 15- to 21 -year followup study. J Bone Joint Surg [Br] 2008;90-B:27-30.

3. Eingartner C, Volkmann R, Winter E, et al. Results of an uncemented straight femoral shaft prosthesis after 9 years of follow-up. J Arthroplasty 2000;15:440-7.

4. Glassman AH, Bobyn JD, Tanzer M. New femoral designs: do they influence stress shielding? Clin Orthop 2006;:453:64-74.

5. Bargar WL. Shape the implant to the patient: a rationale for the use of custom-fit cementless total hip implants. Clin Orthop 1989;249:73-8.

6. Noble PC, Alexander JW, LindahI LS, et al. The anatomic basis of femoral componenet design. Clin Orthop 1988;235:148-65.

7. Wettstein M, Mouhsine E, Argenson JN, et al. Three-dimensional computed cementless custom femoral stems in young patients: midterm followup. Clin Orthop 2005; $437: 169-75$

8. Akbar M, Aldinger G, Krahmer K, Bruckner T, Aldinger PR. Custom stems for femoral deformity in patients less than 40 years of age: 70 hips followed for an average of 14 years. Acta Orthop 2009;80:420-5.

9. Sakai T, Sugano N, Ohzono K, Lee SB, Nishii T. The custom femoral component is an effective option for congenital hip dysplasia. Clin Orthop 2006;451:146-53.

10. Flecher X, Parratte S, Aubaniac JM, Argenson JN. Three-dimensional customdesigned cementless femoral stem for osteoarthritis secondary to congenital dislocation of the hip. J Bone Joint Surg [Br] 2007;89-B:1586-91.

11. Flecher $X$, Pearce 0 , Parratte S, Aubaniac JM, Argenson JN. Custom cementless stem improves hip function in young patients at 15-year followup. Clin Orthop 2009; 468:747-55.

12. Dawson J, Fitzpatrick R, Carr A, Murray D. Questionnaire on the perceptions of patients about total hip replacement. J Bone Joint Surg [Br] 1996;78-B:185-90.

13. Klassbo M, Larsson E, Mannevik E. Hip disability and osteoarthritis outcome score: an extension of the Western Ontario and McMaster Universities Osteoarthritis Index. Scand J Rheumatol 2003;32:46-51
14. Harris WH. Traumatic arthritis of the hip after dislocation and acetabular fractures: treatment by mold arthroplasty: an end-result study using a new method of result evaluation. J Bone Joint Surg [Am] 1969;51-A:737-55.

15. Engh CA Jr, Sychterz C, Engh C Sr. Factors affecting femoral bone remodelling after cementless total hip arthroplasty. J Arthroplasty 1999;14:637-44.

16. Brooker AF, Bowerman JW, Robinson RA, Riley LH Jr. Ectopic ossification following total hip replacement: incidence and a method of classification. J Bone Joint Surg [Am] 1973;55-A:1629-32.

17. Manaster JF, Andrews CL, Conway F, Fleckenstein JL, Kaplan PA. Musculoskeletal radiology. Radiology 1996;198:618-21.

18. Gruen TA, McNeice GM, Amstutz HC. "Modes of failure" of cemented stem-type femoral components: a radiographic analysis of loosening. Clin Orthop 1979;141:17-27.

19. McCullough CJ, Remedios D, Tytherleigh-Strong G, Hua J, Walker PS. The use of hydroxyapatite-coated CAD-CAM femoral components in adolescents and young adults with inflammatory polyarthropathy: ten-year results. J Bone Joint Surg [Br] 2006;88-B:860-4.

20. Brooker AF, Bowerman JW, Robinson RA, Riley LH Jr. Ectopic ossification following total hip replacement: Incidence and a method of classification. J Bone Joint Surg [Am] 1973;55-A:1629-32.

21. Kobayashi S, Eftekhar NS, Terayama K, Joshi RP. Comparative study of total hip arthroplasty between younger and older patients. Clin Orthop 1997;339:140-51.

22. Malchau H, Herberts P, Eisler T, Garellick G, Söderman P. The Swedish total hip replacement register. J Bone Joint Surg [Am] 2002;84-A(Suppl 1):2-20.

23. Glyn-Jones S, Pandit H, Kwon YM, et al. Risk factors for inflammatory pseudotumour formation following hip resurfacing. J Bone Joint Surg [Br] 2009;91-B:1566-74.

24. McNally SA, Shepperd JA, Mann CV, Walczak JP. The results at nine to twelve years of the use of a hydroxyapatite-coated femoral stem. J Bone Joint Surg [Br] 2000;82-B:378-82.

25. Loupasis G, Morris EW, Hyde ID. The Furlong hydroxyapatite-coated total hip replacement in patients under age 51: a 6-year follow-up study. Acta Orthop Belg 1998;64:17-24.

26. Skinner JA, Kroon PO, Todo S, Scott G. A femoral component with proximal HA coating: an analysis of survival and fixation at up to ten years. J Bone Joint Surg [Br] 2003;85-B:366-70.

27. Epinette JA, Manley MT. Uncemented stems in hip replacement: hydroxyapatite or plain porous: does it matter?: based on a prospective study of HA Omnifit stems at 15years minimum follow-up. Hip Int 2008;18:69-74.

28. Bidar R, Kouyoumdjian P, Munini E, Asencio G. Long-term results of the ABG-1 hydroxyapatite coated total hip arthroplasty: analysis of 111 cases with a minimum follow-up of 10 years. Rev Chir Orthop Traumatol 2009;95:579-87.

29. Owen TD, Moran CG, Smith SR, Pinder IM. Results of uncemented porous-coated anatomic total hip replacement. J Bone Joint Surg [Br] 1994;76-B:258-62.

30. Mannan K, Freeman MA, Scott G. The Freeman femoral component with hydroxyapatite coating and retention of the neck: an update with a minimum follow-up of 17 years. J Bone Joint Surg [Br] 2010;92-B:480-5.

31. Götze C, Rosenbaum D, Hoedemaker J, Bottner F, Steens W. Is there a need of custom-made prostheses for total hip arthroplasty?: gait analysis, clinical and radiographic analysis of customized femoral components. Arch Orthop Trauma Surg 2009;129:267-74

32. No authors listed. National Institute for Clinical Excellence (NICE): Technology Appraisal Guidance No. 2. Guidance on the selection of prosthesis for primary total hip replacement. http//www.nice.org.uk/Guidance/TA2 (date last accessed 30 March 2010).

33. No authors listed. NHS Supply Chain: ODEP Database. http://www.supplychain.nhs.uk (date last accessed 17 June 2010).

34. Kold S, Bechtold JE, Ding M, et al. Compacted cancellous bone has a spring-back effect. Acta Orthop Scand 2003;74:591-5.

35. Hua J, Walker PS, Muirhead-Allwood W, Bentley G, McCullough CJ. The rationale for CAD-CAM uncemented custom hips: an interim assessment. Hip Int 1995;5:52-62.

36. Galante J. Evaluation of results of total hip replacement. J Bone Joint Surg [Am] 1990;72-A:159-60.

37. Poss R, Clark CR, Heckman JD. A concise format for reporting the longer-term follow-up status of patients managed with total hip arthroplasty. J Bone Joint Surg [Am] 2001;83-A:1779-81

38. Belmont PJ Jr, Powers CC, Beykirch SE, et al. Results of the anatomic medullary locking total hip arthroplasty at a minimum of twenty years: a concise follow-up of previous reports. J Bone Joint Surg [Am] 2008;90-A:1524-30.

39. Blakey CM, Eswaramoorthy VK, Hamilton LC, Biant LC, Field RE. Mid-term results of the modular ANCA-Fit femoral component in total hip replacement. $J$ Bone Joint Surg [Br] 2009;91:1561-5. 